\title{
Talking About Racism with Patients
}

\author{
Somnath Saha, MD, MPH ${ }^{1,2,3}$ (1) and Lisa A. Cooper, MD, MPH,
}

${ }^{1}$ Center to Improve Veteran Involvement in Care, VA Portland Health Care System, Portland, OR, USA; ${ }^{2}$ Division of General Internal Medicine \& Geriatrics, Oregon Health \& Science University, Portland, OR, USA; ${ }^{3}$ Division of General Internal Medicine, Department of Medicine, Johns Hopkins University School of Medicine, Baltimore, MD, USA; ${ }^{4}$ Johns Hopkins Center for Health Equity, Baltimore, MD, USA.

$J$ Gen Intern Med 36(9):2827-8

DOI: $10.1007 / \mathrm{s} 11606-021-06821-6$

() This is a U.S. government work and not under copyright protection in the

U.S.; foreign copyright protection may apply 2021

$\mathrm{D}$ uring the past year, high-profile acts of racist violence against Black and Asian Americans have prompted declarations of racism as a public health crisis that health professionals must address. ${ }^{1}$ In response, some physicians have suggested opening conversations about racism with patients of color. Though well-intended, this could have unintended consequences. Some patients may not trust doctors from another racial/ethnic group with such a sensitive subject, ${ }^{2}$ or they may simply prefer not to discuss it during a clinical visit. Bringing up racism, and particularly acts of racist violence, may open emotional wounds that physicians are not equipped to heal. Many physicians have unconscious biases that can impair communication with patients from stigmatized groups, ${ }^{3}$ which may be particularly problematic when talking about racism. For all these reasons, broaching the subject of racism carries significant risk of damaging doctor-patient relationships if not handled carefully.

But avoiding the subject also carries risk. Physicians have been shown to sidestep the emotional concerns of patients of color. ${ }^{4}$ At a time when people are equating silence with complicity, avoiding conversations about racism may risk patients' wondering about their doctors' compassion and humanity.

We suggest physicians approach the subject of racism as they would other potential sources of grief or trauma, conveying openness to listening and staying attuned to emotional cues, ${ }^{4}$ without forcing undesired conversations. We favor a permissive approach of opening the door for patients to express their feelings ("This has been a challenging time for many people of color - how are you holding up?") and being prepared to listen reflectively, with empathy and sensitivity. Ideally these conversations should happen within established relationships characterized by mutual trust, respect, and understanding.

Received January 12, 2021

Accepted April 8, 2021

Published online May 4, 2021
When talking about racism, it is important to remember that people have diverse opinions and experiences, and it is difficult to suggest words or actions appropriate for every person or circumstance. However, in our research on race and communication, and in our own personal experiences, we have observed several common missteps that physicians might avoid to more effectively express empathy when talking about racism.

Doubt and Dismissiveness. It is easy to see racism in hate crimes or police brutality. Less visible but far more insidious is the daily experience of microaggressions and other racist acts that do not make headlines. People who don't experience racism themselves tend to doubt its pervasiveness and dismiss testimonials of racial discrimination as overinterpretations of "harmless" behavior. Black patients, in particular, often complain of not feeling heard or believed by clinicians; ${ }^{5}$ having their experience of racism doubted or dismissed could do irreparable harm to the doctor-patient relationship.

Surprise and Incredulity. Sometimes people say "I can't believe that happened" or "This is not who we are," to express shared outrage. But those statements betray a lack of awareness of the pervasiveness of racism. Acts of racial discrimination and aggression should not be surprising, because they are not new or uncommon, and the inattention and silence of people who have had the privilege of not experiencing racism has allowed it to persist. This may not be who we wish to be as a society, but it is who we are.

Defensiveness. When discussing racism, patients may tell us things about our profession, institutions, and even ourselves that are difficult to hear. We must allow ourselves to be vulnerable and willing to hear things that make us uncomfortable, using them as opportunities for self-reflection and growth, without defensiveness.

Diluting the Focus. Racism can be uncomfortable to talk about, causing a tendency to divert conversations towards the safer ground of socioeconomic inequality more broadly, invoking other disadvantaged groups (e.g., the poor or disabled). While we may understandably wish to denounce all forms of inequity, when talking with patients about their 
experience of racism, the focus should be on racial discrimination and injustice.

Colorblind Language. It is tempting to say we are all one (human) race and that our skin color shouldn't matter. Indeed it shouldn't, but countless acts of racist violence make it abundantly clear that it does. Colorblind idealism is a luxury afforded by White privilege. It wishes away, rather than confronts, the injustices endured by those who experience racism, and invalidates their lived experiences.

Conflating Solidarity in Fighting Racism with Solidarity in Experiencing It. People say things like "Racism hurts us all," with good intentions, to show solidarity and support. But those statements can imply that we are all similarly affected, which we decidedly are not. Racism may hurt the majority indirectly, but it does not negatively affect their daily lives. It is important to acknowledge that the impact of racism has been borne by communities of color, and that the responsibility for change should be borne by everyone.

Asserting That Racist Violence Shouldn't Be Happening "Anymore". While it is admittedly dismaying that racist violence has not abated despite societal progress, saying that it shouldn't be happening now can imply that it was somehow more tolerable in the past. It was never tolerable.

Qualifying Condemnations of Racism. During the protests of the murders of George Floyd and other Black Americans, people often couched statements about police brutality with conditional clauses like, "While I don't condone violent protest..." or "I understand the risks police take, but..." Opposing violent protest or appreciating the police are common sentiments, but they are not relevant to condemning racism. One can denounce racist violence without bringing in other issues that serve as asterisks.

Talking More Than Listening. Physicians tend to dominate conversations, particularly with Black patients. ${ }^{6}$ This tendency may be exacerbated among physicians eager to express solidarity and empathy. Particularly for White physicians, most of whom cannot fully understand the experience of racism, empathy should involve more listening than speaking.

Failing to See Racism as a Systemic Problem. Even more pernicious than acts of racial discrimination are the myriad structural ways in which racism has created and maintains social inequality. It is important to see racism as not only the overtly discriminatory actions of a few people, but the pervasive racial inequality evident in all realms of society, from criminal justice and employment to education and health care. These are social determinants of health that profoundly influence people's lives.
Some physicians may feel inadequately educated to talk about racism. But part of our professional commitment is to be lifelong learners. Until recently, none of us knew about the virus SARS-CoV-2. But we learned quickly so that, even without treatments to offer, we could keep our patients safe and care for those affected. Racism amplified the unequal impact of COVID-19 and will continue to be a threat to public health long after the pandemic is over. While we cannot offer immediate cures for a centuries-old societal affliction, we can equip ourselves to address the suffering it causes. We can educate ourselves about the origins and history of race, understand White privilege, and recognize our own biases and how they may contribute to inequities in health care. ${ }^{7}$ We can commit to personal reflection and behavior change and advocacy in our professional networks and organizations. And as a profession of healers, we can give our patients a safe, empathic, and affirming space to talk about their experiences of racism, and its effect on their health and lives, should they wish to.

Acknowledgements: Dr. Saha is supported by the Department of Veterans Affairs.

Corresponding Author: Somnath Saha, MD, MPH; Center to Improve Veteran Involvement in Care, VA Portland Health Care System, Portland, OR, USA (e-mail: sahas@ohsu.edu).

\section{Declarations:}

Conflict of Interest: The authors declare that they do not have a conflict of interest.

Disclaimer: The views expressed in this article are those of the authors and do not necessarily reflect the position or policy of the Department of Veterans Affairs or the US government.

\section{REFERENCES}

1. American Public Health Association. Declarations of racism as a public health issue. 2020. https://www.apha.org/topics-and-issues/health-equity/racism-and-health/racism-declarations. Accessed January 8, 2020.

2. Saha S, Beach MC. Impact of physician race on patient decision-making and ratings of physicians: a randomized experiment using video vignettes. J Gen Intern Med. 2020;35:1084-91.

3. Cooper LA, Roter DL, Carson KA, et al. The associations of clinicians' implicit attitudes about race with medical visit communication and patient ratings of interpersonal care. Am J Public Health. 2012;102:979-87.

4. Park J, Beach MC, Han D, Moore RD, Korthuis PT, Saha S. Racial disparities in clinician responses to patient emotions. Patient Educ Couns. 2020; 103:1736-44.

5. Beach MC, Branyon E, Saha S. Diverse patient perspectives on respect in healthcare: a qualitative study. Patient Educ Couns. 2017;100:2076-80.

6. Johnson RL, Roter D, Powe NR, Cooper LA. Patient race/ethnicity and quality of patient-physician communication during medical visits. Am J Public Health. 2004;94:2084-90.

7. MedEd Portal: Anti-racism in Medicine Collection. 2020. https://www. mededportal.org/anti-racism. Accessed August 21, 2020.

Publisher's Note: Springer Nature remains neutral with regard to jurisdictional claims in published maps and institutional affiliations. 